\title{
It's time for the US and Muslims to work together
}

\section{Each side has problems to solve and much to gain from contact with the wider world.}

Sir - After 11 September 2001, the United States adopted precautionary measures to protect its people and institutions. Many institutions have slammed their doors to Muslim scientists. As a scientist and writer interested in science and society, I am concerned that the current political and emotional upheavals will severely handicap the growth of science in the Islamic world.

Discriminatory US policies discourage US institutions from recruiting Muslim scientists. These policies include the US Department of Agriculture's ban on scientists from several countries including traditional Islamic areas; extensive background checks on Muslims; and the recent law requiring men from Islamic countries to report to immigration offices.

These exclusion policies cover a broad range of science, from agriculture to IT, and will severely inhibit the growth of science in the Islamic world. To avert catastrophe, all groups - Muslims,
Americans and Europeans - must act.

Muslims must recognize the need to spend petrochemical wealth in establishing centres of scientific excellence and creating an environment conducive to scientific growth in all Islamic countries (not just Arab ones). Muslim nations must formulate relevant $\mathrm{R} \& \mathrm{D}$ programmes, restructure institutions to end corruption and dynastic practices, and collaborate with both Western and newly industrialized states to nurture a strong science base. Finally, Muslims must demand more from their leaders, so that they can become equal to other societies.

US organizations and individual scientists must lobby hard to change post11 September policies that are detrimental to scientific endeavour. US scientists could collaborate, mentor and otherwise assist Muslim scientists. American Muslim scientists must take the lead in Islamic science, as they live in a progressive country.

Europeans can take an active role in bridging the rift between the US and Muslim worlds, filling the vacuum created by US precautionary policies. Europeans are already taking small steps to collaborate with the Arab countries (Nature 423, 906; 2003). This process should be encouraged.

There is an urgent need to reinvigorate the rusted scientific sector of the Muslim world beyond rhetoric, marathon conferences and establishment of skeleton institutions. It requires the concerted effort of politicians, scientists, philanthropists, entrepreneurs and ordinary citizens. There is definitely room for reform and business opportunities in the Islamic world.

The United States was brutally hurt by a few ruthless terrorists, and faces further threats. However, blanket repressive policies in response will cause more harm than good to the world as a whole.

Ahmed M. Dirie

California, USA

adirie2001@yahoo.com

\section{Bomb dosimetry unlikely to change risk estimates}

Sir - In his News and Views article "A dose of the bomb" (Nature 424, 495-496; 2003) about the impact of the new A-bomb dosimetry on radiation-risk estimates, Mark Little argues that the risks of $\gamma$-ray exposure should become more reliable. Two other factors suggest that the new dosimetry is likely to have little or no impact on risk estimates for doses that are occupationally or environmentally relevant.

The US National Council on Radiation Protection and Measurements (NCRP Report No. 126, NCRP, Bethesda, 1997) has determined the dose-rate effectiveness factor to be the main source of uncertainty in risk estimates, accounting for about $40 \%$ of total uncertainty. Overall, dosimetry uncertainties account for less than $10 \%$ of the total.

Dose-rate effectiveness factors must be applied to A-bomb-derived risk estimates to account for differences in temporal dose delivery. The bomb exposed people to very high dose rates (essentially instantaneous exposure), whereas risk estimates are usually applied to occupational or environmental situations where the dose is delivered at a significantly lower rate and risks are assumed to be lower because of biological repair mechanisms.

The second source of uncertainty is dose extrapolation. A-bomb risks are based on excess cancer deaths in people exposed to doses greater than $200 \mathrm{mSv}$ (D. A. Pierce et al. Radiat. Res. 146, 1-27; 1996). Below this dose the total excess number of cancer deaths is too small to be used reliably in risk estimation. Accordingly, risks calculated from high-dose data are extrapolated using the linear non-threshold theory to predict risks at small doses. Assuming that occupational and environmental doses are around $2 \mathrm{mSv}$ per year, dose extrapolation is significant and the theoretically derived risks are highly uncertain.

\section{Kenneth L. Mossman}

School of Life Sciences, University Office of Radiation Safety, Arizona State University, Tempe, Arizona 85287-3501, USA

Mark Little replies - I am grateful for Dr Mossman's comments on my article. As I stated in the penultimate paragraph, sources of uncertainty other than the dosimetry have to be taken into account in deriving risk estimates from the A-bomb data. Constraints of space did not allow me to go into these in detail. I would concur with Dr Mossman that extrapolation of risks to low doses and low dose rates is one of the more substantial of these, others being the extrapolation of risks to the end of life and across populations, for example from a Japanese to a UK population (NCRP Report No. 126, NCRP, Bethesda, 1997).

The various sorts of bias (selection, ascertainment and so on) to which epidemiological studies are prone should also be considered. As discussed in my article, selection bias in A-bomb survivors may be significant, and as with the problems of extrapolation of dose and dose rate, may largely invalidate the A-bomb risk estimates. However, as noted previously, cancer risks derived from A-bomb survivor data are statistically consistent with those observed in groups exposed at moderate-to-low doses and dose rates (M. P. Little et al. Radiat. Res. 151, 218-224; 1999; R. Wakeford et al. Int. J. Radiat. Biol. 79, 293-309; 2003).

\section{Nothing new under the Sun?}

Sir - J. M. Gordon and colleagues, in their Brief Communication "Surgery by sunlight on living animals" (Nature 424, 510; 2003), describe the use of a solar photocoagulator to necrose a rat liver lesion in what they believe to be "the first time that intense incoherent light has been applied successfully in an interstitial medical procedure". They may be surprised to learn that such a technique played a significant role in the development of a modern clinical ophthalmic practice: retinal photocoagulation. The German ophthalmologist Gerhard MeyerSchwickerath (G. Meyer-Schwickerath Ber. Dtsch. Ophthalmol. Ges. 55, 256-259; 1949) not only undertook the repair of retinal breaks by focused sunlight, but also designed the optical instrumentation that bears his name: the Meyer-Schwickerath coagulator. Merrick Moseley

Department of Ophthalmology, Imperial College, St Dunstan's Road, London W6 8RP, UK 